\title{
Cessation of seizure-like oscillations by periodic stimulation in a neuron model with dynamic ion concentrations
}

\author{
Jeremy Owen ${ }^{1}$, John R Cressman², Ernest Barreto ${ }^{2 *}$
}

From Twenty First Annual Computational Neuroscience Meeting: CNS*2012

Decatur, GA, USA. 21-26 July 2012

Here we describe the effect of adding periodic forcing to a simple model of a generic neuron with slow $\mathrm{Na}+$ and $\mathrm{K}+$ concentration dynamics [1]. With no stimulation, the model exhibits bursting due to the gradual modulation of ion concentrations, this limit cycle is shown in panel (a) of
Figure 1. We have identified a range of parameter values where periodic stimulation can stop seizure-like bursting by freezing the slow ionic dynamics. Instead of following the large "bursting" limit cycle in the $\mathrm{Na}+\mathrm{K}+$ phase plane, the stimulation forces the model into much smaller loops (a)

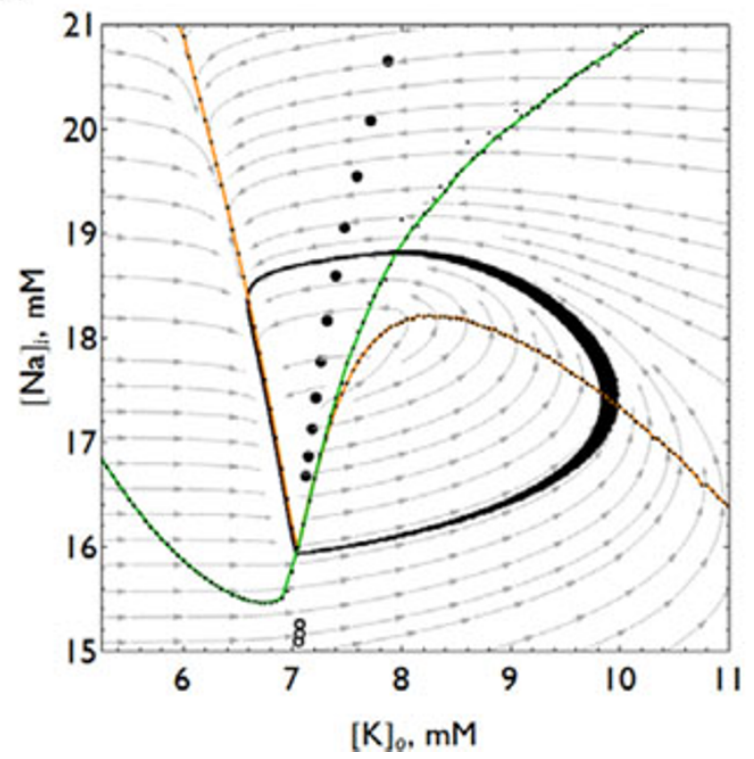

(b)

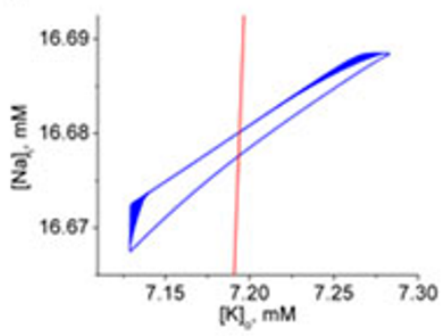

(c)

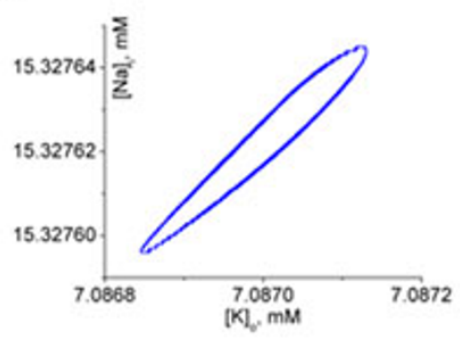

Figure 1 Under stimulation, the model trajectory approaches small loops at locations indicated in (a) by closed(excitatory) or open(inhibitory) symbols for various values of stimulation frequency. Frequency increases upwards (downwards) for excitatory (inhibitory) stimulations. (b and c) Close ups of the small trajectories produced by excitatory and inhibitory stimulation.

${ }^{2}$ School of Physics, Astronomy, and Computational Sciences, and The

Krasnow Institute for Advanced Study, George Mason University, Fairfax, VA

22030, USA

Full list of author information is available at the end of the article 
in the ion concentration space. These small trajectories are shown in panels (a) and (b) of Figure 1 for excitatory and inhibitory stimulation respectively.

In the case of excitatory stimulation, the model continues to exhibit spikes in voltage, but only at the stimulation frequency-which can be made much lower than the rate of spontaneous spiking seen in bursting. For other parameter values, the addition of stimulation can reduce the amplitude of the bursts, or in some cases, induce bursts. These results may give insight into previous studies which showed that stimulation via electrodes can stop seizures in slice preparations [2], could help explain the mechanism of action of vagus nerve stimulation as treatment for epilepsy [3], and may provide novel avenues for treatment of epilepsy.

\section{Author details}

${ }^{1}$ Cornell University, Ithaca, NY 14853, USA. ${ }^{2}$ School of Physics, Astronomy, and Computational Sciences, and The Krasnow Institute for Advanced Study, George Mason University, Fairfax, VA 22030, USA.

Published: 16 July 2012

\section{References}

1. Cressman JR, Ullah G, Ziburkus J, Schiff SJ, Barreto E: The influence of sodium and potassium dynamics on excitability, seizure, and the stability of persistent states:I. Single neuron dynamics. Journal of Computational Neuroscience 2009, 26(2):159-170.

2. Khosravani H, Carlen PL, Valezsquez JLP: The control of Seizure-Like Activity in the Rat Hippocampal Slice. Biophysical Journal 2003, 84(1):687-695

3. Groves DA, Brown VJ: Vagal nerve stimulation: a review of its applications and potential mechanisms that mediate its clinical effects. Neuroscience \& Biobehavioral Reviews 2005, 29(3):493-500.

doi:10.1186/1471-2202-13-S1-P182

Cite this article as: Owen et al:: Cessation of seizure-like oscillations by periodic stimulation in a neuron model with dynamic ion concentrations. BMC Neuroscience 2012 13(Suppl 1):P182.

\section{Submit your next manuscript to BioMed Central} and take full advantage of:

- Convenient online submission

- Thorough peer review

- No space constraints or color figure charges

- Immediate publication on acceptance

- Inclusion in PubMed, CAS, Scopus and Google Scholar

- Research which is freely available for redistribution

Submit your manuscript at www.biomedcentral.com/submit 